\title{
AS EVIDÊNCIAS RACISTAS E SEXISTAS NO CAMPO DE ATUAÇÃO DA LEI MARIA DA PENHA: UMA LEITURA PELA PERSPECTIVA DA COLONIALIDADE
}

\author{
Fernanda da Silva Lima ${ }^{1}$ \\ Carolina Rovaris Pezente ${ }^{2}$ \\ Jóicy Rodrigues Teixeira Hundertmark ${ }^{3}$
}

RESUMO: O tema principal deste artigo é a Lei Maria da Penha, em especial a violência doméstica contra mulheres negras. O objetivo geral, é verificar como ocorre a proteção de mulheres negras em situação de violência doméstica, na Lei Maria da Penha em uma perspectiva interseccional. Trabalhar-se-á com pesquisa de abordagem dedutiva, em procedimento monográfico, de tipo teórica e qualitativa com instrumento de coleta de dados, a pesquisa do tipo bibliográfica. Conclui-se que mesmo sendo uma conquista inegavelmente importante, esta Lei não alcança todas as mulheres, não alcança todas as mulheres em decorrência das fragilidades estruturais em operacionalizar a própria lei.

Palavras-chave: Interseccionalidade; Lei Maria da Penha; mulheres negras; racismo; violência contra mulheres negras.

THE RACIST AND SEXIST EVIDENCE IN THE FIELD OF THE MARIA DA PENHA LAW: A READING FROM THE PERSPECTIVE OF COLONIALITY

\footnotetext{
${ }^{1}$ Orientadora do artigo que está em construção, mas que ora se apresenta para garantir visibilidade à discussão proposta pela relevância do tema. Doutora e Mestra em Direito pelo PPGD/UFSC, Professora Permanente no Programa de Pós-Graduação em Direito da UNESC/SC, Coordenadora do NEGRA - Núcleo de Estudos em Gênero e Raça da UNESC, Integrante do Núcleo de Estudos em Direitos Humanos e Cidadania (NUPEC), atua na área de direito público com linha de pesquisa Direitos Humanos, Cidadania e novos direitos com interesse nos seguintes temas: teoria crítica dos direitos humanos, relações raciais, feminismos negros, infâncias, estudos pós-coloniais, decoloniais e anti-coloniais. E-mail: *felima.sc@gmail.com ${ }^{2}$ Mestra em Direito pelo Programa de Pós-Graduação em Direito da Universidade do Extremo Sul Catarinense (UNESC). Pesquisadora do Grupo de Pesquisa em Direitos Humanos, Relações Raciais e Feminismo[s]. Pesquisadora no Núcleo de Pesquisas em Direitos Humanos e Cidadania (NUPEC). Bolsista pelo Programa FUNDES/UNIEDU. Graduada em Direito pela UNESC. E-mail: *carolrpezente@gmail.com ${ }^{3}$ Mestranda em Direito pelo Programa de Pós-Graduação em Direito da Universidade do Extremo Sul Catarinense (UNESC). Pesquisadora do Grupo de Pesquisa em Direitos Humanos, Relações Raciais e Feminismo[s]. Pesquisadora no Núcleo de Pesquisas em Direitos Humanos e Cidadania (NUPEC). Bolsista pelo Programa de Suporte à Pós-Graduação de Instituições Comunitárias de Ensino Superior (PROSUC) - CAPES. Graduada em Direito pela UNESC. E-mail: *joicy.teixeira@hotmail.com
} 
ABSTRACT: The article's main theme is the Maria da Penha Law, especially domestic violence against black women. The general objective is to verify how the protection of black women in situations of domestic violence occurs, in the Maria da Penha Law in an intersectional perspective. We'll work with deductive approach research, in a monographic procedure, of a theoretical and qualitative type and using the bibliographic type of research as an instrument of data collection. Concluding, even though it's an undeniably important achievement, the Maria da Penha Law doesn't reach all women, limiting itself only to those that fit the universal perspective.

Keywords: Intersectionality; Maria da Penha Law; black women; racism; violence against black women.

\section{APRESENTAÇÃO}

O presente artigo tem o escopo de realizar um estudo sobre a Lei Maria da Penha, observando a forma como incorpora demandas de mulheres em sua diversidade, tendo em vista que as teorias feministas abstratas e hegemônicas não dão conta da pluralidade de demandas e interseccionalidades. Precisamos esclarecer que este é um artigo que se encontra em atual construção, mas que estamos apresentando neste momento visando garantir a visibilidade dessa discussão de tamanha relevância.

Focamos na Lei Maria da Penha, pois os estudos sobre ela, geralmente, priorizam uma abordagem única de gênero, que não destaca as interseccionalidades que diferenciam as realidades de cada mulher. Essa dificuldade acaba reproduzindo as relações de poder e de desigualdade já presentes em nossa sociedade (SANTOS, 2017). Assim, precisamos sempre rever os privilégios da branquitude, não isentos em feministas ou intelectuais (BERNARDES, 2018).

Cabe pontuar a necessidade de construção de agendas em comum nas lutas das mulheres, reconhecendo as subjetividades e as opressões que nem sempre são as mesmas, por exemplo, as mulheres negras carregam além da opressão sexista o racismo enquanto estruturais e estruturantes das desigualdades no Brasil. A construção de agendas em comum nas lutas das mulheres, reconhecendo as subjetividades e as opressões, por isso a luta antirracista precisa ser pautada também por feministas brancas, por isso a luta antirracista 
precisa ser pautada também por feministas brancas, e, para se iniciar na luta antirracista, não basta reconhecer o racismo no feminismo, mas lutar contra a opressão racista também (hooks, 2019).

Além do mais, há uma confusão entre lugar de fala e representatividade. Uma pessoa em condição de privilégio pode não representar aquela que é marginalizada, mas não pode se desresponsabilizar. A fala representada pelo seu lugar de falar rompe com a ideia de que apenas subalternizados/as podem falar (com a noção de que aqueles/as na hegemonia estão isentos de responsabilidade). Não esquecendo que as pessoas pertencentes aos grupos privilegiados, mesmo que conscientes e antirracistas, não deixam de se beneficiar pelas opressões de outros grupos (RIBEIRO, 2017).

É exatamente por esse motivo que viemos por meio deste trabalho, enquanto mulheres brancas, na condição de orientandas de uma professora negra, que reconhecem sua condição de privilégio nessa sociedade que não é assumidamente racista, diante do mito da democracia racial, identificando o nosso lugar de fala, mas sem deixar de nos posicionarmos enquanto mulheres comprometidas com a luta antirracista, anti-imperialista e antissexista, diante da necessidade de união, buscando trazer pontos indispensáveis para a violência doméstica que, apesar da existência de políticas públicas, continua vitimizando mulheres negras, enquanto diminuem percentuais de violência contra mulheres brancas.

Isso porque, como pontua Yuderkys Espinosa Miñoso (2020, p. 8), um feminismo decolonial também "percorre, revisa e dialoga com o pensamento e as produções que vêm sendo desenvolvidas por [...] acadêmicas brancas comprometidas com subalternidade na América Latina e no mundo".

A relevância desse artigo se encontra na inexistência de preocupação com as mulheres negras em uma grande quantidade de estudos que têm como centralidade a teoria hegemônica dos movimentos de mulheres. O que se parece muito, conforme será devidamente apresentado no segundo tópico deste artigo, com a teoria hegemônica de direitos humanos que não abarca a diversidade de pessoas, caracterizada para o Homem Vitruviano (branco, europeu, de classe média/alta), por meio de seu universalismo abstrato.

Essa pesquisa foi muito motivada ao que temos discutido e pontuado no Grupo de Pesquisa ao qual somos vinculadas: o NEGRA - Núcleo de Estudo em Gênero e Raça. E, também nessa perspectiva, esse estudo é de vital importância para o Programa de PósGraduação em Direito da Universidade do Extremo Sul Catarinense, no qual participamos na 
condição de mestrandas, para que o próprio programa, enquanto perspectiva de direitos humanos, demonstre a preocupação com os direitos de todas as pessoas, não apenas a universalidade branca.

Buscamos sair das discussões de cunho apenas acadêmico para auxiliar de forma real e verdadeira além dos muros da universidade. Por esse motivo, esse artigo busca a ampliação das políticas públicas que, no dia a dia, não dão a atenção necessária às questões de raça.

O objetivo principal é verificar como se dá a proteção de mulheres negras em situação de violência doméstica na Lei Maria da Penha em uma perspectiva interseccional. Desdobrando-se em outros três: apresentar a violência doméstica no contexto da Lei Maria da Penha; situar o racismo e o sexismo no contexto brasileiro e na Lei Maria da Penha; por fim, demonstrar os limites e possibilidades da Lei Maria da Penha e a emergência dos feminismos negros, tendo a interseccionalidade como categoria de análise. Para alcançar o objetivo proposto trabalhar-se-á com pesquisa de abordagem dedutiva, em procedimento monográfico, de tipo teórica e qualitativa, em uma pesquisa do tipo bibliográfica, analisando o que a legislação traz e o que oculta.

\section{A VIOLÊNCIA DOMÉSTICA NO CONTEXTO DA LEI MARIA DA}

\section{PENHA}

A mobilização de mulheres ao redor do mundo possibilitou a adoção de inúmeros direitos, antes não previstos pela universalidade dos direitos humanos, pois apesar de se dizer universalista, não abarca todas as pessoas, como se desenvolverá ao longo deste tópico. Porém, apesar da importância e da relevância incomensuráveis que os movimentos de mulheres tiveram para conquistas dos direitos humanos das mulheres, acabam também voltando-se a uma hegemonia branca, que universaliza as mulheres, reproduzindo na prática aquilo que já se percebeu no discurso tradicional dos direitos humanos, ou seja, a abstração e neutralidade e, consequentemente, a invisibilidade para outros marcadores de opressão, como a raça.

Os movimentos de mulheres buscam pela reforma do tratamento da violência doméstica desde 1970 no Brasil. A trajetória, então, consolidou-se de forma mais especial em 2006, com a criação da Lei Maria da Penha, símbolo da conquista diante do esforço dos movimentos de mulheres (CAMPOS; CARVALHO, 2011). A lei veio para desconstruir o 
tratamento legal anterior, ouvindo mulheres em debates que antecederam a sua criação. Portanto, as mulheres tiveram uma participação política importante, enquanto sujeitos políticos na construção legal (CAMPOS, 2011).

Assim, é importante destacar que durante, aproximadamente, 30 anos, mulheres atuaram para que o tema da violência doméstica ingressasse no cenário político brasileiro (CAMPOS, 2017b). Já em meados de 1990, cogitam recorrer às instâncias internacionais de direitos humanos, tendo em vista a impunidade dos assassinatos de mulheres que estava acontecendo no Brasil. Encaminhando para a Comissão Interamericana de Direitos Humanos dois casos relevantes no país (SANTOS, 2008).

O primeiro caso é de Márcia Leopoldi, que foi assassinada pelo ex-namorado, encaminhado em 1996. O segundo caso é de Maria da Penha Maia Fernandes, que sofreu uma dupla tentativa de assassinato pelo marido, encaminhado em 1998. Estes dois casos ressaltam a necessidade de alterar o sistema de justiça criminal brasileiro, buscando prevenir e coibir a prática da violência doméstica contra mulheres (SANTOS, 2008).

Diante da visibilidade do caso Maria da Penha, vale uma pontuação especial sobre o caso dela. Ela foi vítima de duas tentativas de homicídio pelo marido Marco Antônio Heredia Viveros, o primeiro aconteceu em 29 de maio de 1983, quando ele simulou um assalto e atirou nas costas de Maria de Penha enquanto dormia. Como consequência deste fato, ela perdeu os movimentos das pernas, aos 38 anos (BERNARDES, 2014); (SANTOS, 2008).

Semanas depois de voltar do hospital, o marido tentou eletrocutá-la durante o banho. Dias antes do fato forçou-a a assinar um seguro de vida em benefício do marido e a venda de seu carro. Depois desse segundo fato, ela pediu o divórcio e o denunciou. Em 28 de setembro de 1984, o Ministério Público formalizou a denúncia (BERNARDES, 2014).

Entre essa data e o envio à Corte Interamericana de Direitos Humanos, aconteceram dois julgamentos por júri, ambos condenando-o. Apesar disso, permaneceu em liberdade durante 19 anos. Após recorrer inúmeras vezes da sentença, incluindo práticas de corrupção, foi preso apenas em 2002, pouco tempo antes do crime prescrever, o que só aconteceu por pressão da Comissão Interamericana de Direitos Humanos, após inúmeras solicitações de informações do Estado brasileiro, que se mantinha inerte (BERNARDES, 2014); (SANTOS, 2008).

Em 2001, a responsabilização do Brasil pelo caso de Maria da Penha, torna-se internacional, diante da negligência do país quanto à dupla tentativa de homicídio por parte do 
marido, bem como a conivência por parte do Estado (CAMPOS, 2017b). Oportunidade em que se expediu um relatório por parte da Comissão Interamericana de Direitos Humanos solicitando a alteração normativa sobre a violência doméstica no Estado brasileiro, dentre outras solicitações (BERNARDES, 2019).

Através desses casos, pode-se observar o descaso do governo brasileiro com as denúncias internacionais para os casos de violência doméstica contra mulheres e a lentidão dos casos que passam pelo Sistema Interamericano de Direitos Humanos. Isso demonstra a importância que os movimentos de mulheres tiveram para a politização e a materialização dos direitos humanos das mulheres, buscando a alteração legal para o tratamento da violência doméstica (SANTOS, 2008).

Nesse sentido, por meio da proposição dos movimentos de mulheres, a Lei Maria da Penha trouxe o reconhecimento da violência doméstica realizada em âmbito privado, retirando a noção de crime de menor potencial ofensivo, para uma perspectiva mais integral. Contudo, obstáculos ainda existem, tendo em vista que a justiça penal tradicional vem substituindo a centralidade que deveria ser a mulher, diante da colonialidade que nega gênero e corpos de mulheres, principalmente de mulheres negras (CAMPOS, 2017a).

Porém, apesar da importância que a lei produziu para os casos de violência doméstica e para os direitos humanos das mulheres, precisamos ter em mente que se volta, principalmente, para o ser mulher em sua universalidade, o que, assim como acontece com os direitos humanos de perspectiva universal da ONU, não consegue se efetivar a todas as pessoas.

Isso é claramente perceptível através dos dados sobre a violência que demonstra que, enquanto diminuem os índices de mulheres não negras, a violência contra a mulher negra só aumenta. Fato que será melhor exposto no tópico 3, mas não se pode deixar de mencioná-lo desde já, enquanto importante norteador deste artigo.

Diante disso, gostaríamos de ressaltar que o contexto de criação dos direitos humanos veio como resultado do nazismo, que antes foi legitimado e absolvido pelas suas vítimas, porque era contra povos não europeus, na civilização ocidental. $O$ burguês humanitarista e cristão levou o hitlerismo a outros lugares, "Hitler vive dentro nele", porque não é a prática que se criminaliza, mas a prática realizada contra outros homens brancos. Dando margem ao processo de subalternização que só havia acontecido com pessoas negras da África, árabes na Argélia e coolies na Índia (CÉSAIRE, 1978). 
Com a perda da guerra por parte da Alemanha nazista e seus aliados, surgiu a necessidade de se pensar os direitos humanos nessa perspectiva universal. Criam-se, então, os direitos humanos universais que, supostamente, destinam-se a todas as pessoas, através da Declaração Universal dos Direitos Humanos, de 1948. Ela é considerada até hoje o principal marco sobre o tema, estabelece princípios de proteção às pessoas, atribui responsabilidades aos Estados-membros das Nações Unidas e reafirma a universalidade dos direitos humanos. É clarividente perceber que quando a realidade começa a atingir pessoas brancas, isso causa uma mobilização geral e global, diante da maior comoção.

Os direitos humanos surgem como uma base mínima de direitos, porém, é necessário perceber que o contexto cultural de sua criação é ocidental. Essa noção não retira a importância desses direitos, mas os coloca em um contexto concreto, que demonstra a dificuldade de sua implementação de maneira geral e universal. Portanto, esse mínimo necessário previsto pelos direitos humanos não pode acontecer por meio de imposições ou colonialismos (FLORES, 2009).

Isso advém também do contexto em que esse documento foi criado, pois olhando fotos das pessoas participantes na ocasião, observamos uma presença majoritária masculina e branca. Isso é muito nítido para nos demonstrar que não tem como um documento que se pretende tão universal e abrangente, permanecer com as organizações de poder que se mantêm desde a colonização e reforça as bases estruturais do racismo e do sexismo até os dias de hoje.

Por isso que uma norma pode prever que todas as pessoas possuem direitos, ao mesmo tempo em que, concretamente, os resultados desta norma são muito diferentes dependendo do contexto cultural de cada pessoa. E, se fosse o caso, não haveriam pessoas que não conseguiriam a garantia desses direitos (FLORES, 2009), o que não é a realidade.

Para tentar resolver isso, a teoria crítica dos direitos humanos busca descrevê-los não mais como os simples direitos que garantem a possibilidade de mais direitos, mesmo antes que as pessoas tenham a capacidade para exercê-los. Passariam a ser analisados enquanto processos de luta em busca da afirmação dos direitos humanos, com base no que cada pessoa acha que seja dignidade humana. Os direitos vêm, nesse sentido, em sequência, como resultado dessas lutas (FLORES, 2009).

A partir dessa ideia, unindo essa concepção dos direitos humanos com a Lei Maria da Penha, observamos que as mulheres negras têm denunciado há anos o quanto o sistema 
jurídico segue desumanizando-as com base na raça e o quanto o índice de violências contra seus corpos têm aumentado a despeito do que preconiza a lei. Assim, a mulher universal retratada na Lei Maria da Penha segue subalternizando e objetificando as mulheres negras, ainda que intencionalmente (BERNARDES, 2018).

Nesse sentido, apesar de a Lei Maria da Penha ser muito importante enquanto reconhecimento no campo jurídico, ainda enfrenta alguns obstáculos em sua aplicação. Isso acontece porque as interseccionalidades demonstram que essa violência atinge de maneiras diferentes mulheres brancas, mulheres negras, mulheres negras trans, dentre inúmeras outras formas de opressão (CAMPOS, 2017b).

A lei contempla outras categorias sociais que vão para além do gênero, como o agravo de pena no caso de mulheres com deficiência, a raça enquanto fator de medidas protetivas, a independência de orientação sexual nos casos de violência doméstica. Porém, tem uma definição de violência doméstica que se baseia apenas na categoria gênero, o que leva estudos sobre ela a não adotarem, como regra, a perspectiva interseccional (SANTOS, 2017).

O que nos transparece a necessidade de reconhecer as mulheres como um grupo social que é desigual e heterogêneo, mas não apenas em relação aos homens. Mulheres negras, mulheres trans, mulheres migrantes, mulheres com deficiência, mulheres lésbicas, passam a ser reconhecidas pela jurisprudência como sujeitos de direitos (SANTOS, 2017).

É evidente que a conquista que os movimentos de mulheres trouxeram para o âmbito da violência doméstica, por meio da criação da Lei Maria da Penha, com a inclusão de categorias sociais para destacar algumas formas de opressão, é muito importante. Mas, não se pode deixar de destacar que ela, ainda assim, não consegue ser efetiva para toda e qualquer mulher.

Isso acontece especialmente porque mulheres intelectuais e militantes, em regra, ignoram outras formas de opressão que não o sexismo. Universaliza a mulher com base na opressão comum de gênero. Porém, assim como acontece com os direitos humanos, essa universalidade é insuficiente para a garantia de direitos a todas as pessoas, por isso a importância que as especificidades e as interseccionalidades têm, ou deveriam ter, no âmbito da violência doméstica.

E, como nos propomos desde o início, voltando-se às opressões racistas e sexistas presentes nas realidades de mulheres negras, é indispensável falar sobre o processo de 
colonização e o colonialismo ainda presente em nossa sociedade, para que possamos abrir os olhos quanto aos pactos promovidos narcisicamente pela branquitude e que seguem mantendo inalterada a estrutura de privilégios.

Esse pacto é uma espécie de acordo tácito entre as pessoas brancas para não se reconhecerem como parte essencial na perpetuação das desigualdades raciais no Brasil. Reconhecendo que existe sim a desigualdade racial, mas não é resultado da discriminação e sim por conta da escravização das pessoas negras que, ao que parece, não tem ligação alguma com as pessoas brancas (BENTO, 2002).

O medo e o silêncio são compreensíveis, diante da apropriação e da violação de direitos que durou entre 400 e 500 anos, buscando ações que apaguem a "mancha negra" da história do Brasil. Contudo, o silêncio não apaga o passado (BENTO, 2002). Por isso abordaremos no tópico seguida a colonização.

\section{AS MULHERES NEGRAS NO BRASIL: MARCAS DO RACISMO E DO SEXISMO IMPOSTO PELA MODERNIDADE/COLONIALIDADE}

Antes de mais nada, é importante pontuar que raça não é um termo estático, portanto, está sempre em dinâmica conforme tempo e espaço. Inicialmente era usada como ato de classificação apenas de plantas e animais. Mas, passou a classificar os seres humanos durante a modernidade. No entendimento de conflito, poder e decisão, a raça é um dos pilares para a constituição política e econômica das sociedades modernas. Estando o racismo presente, mediante as relações interpessoais ou nas instituições, como elemento que integra a organização econômica e política da sociedade (ALMEIDA, 2018). O que será melhor observado após o destaque sobre o processo de colonização.

Nesse sentido, adotamos a concepção de racismo proposta por Silvio Almeida (2018, p.25):

O racismo é uma forma sistemática de discriminação que tem a raça como fundamento, e que se manifesta por meio de práticas conscientes ou inconscientes que culminam em desvantagens ou privilégios para indivíduos, a depender do grupo raça ao qual pertençam.

Assim, a classificação das pessoas com base na raça, aconteceu durante o período de expansão e "descobrimentos", que se deu entre os séculos XIV e XVI, onde reconheceu-se a humanidade das pessoas com base no homem branco e europeu. Esse ser universal criado neste momento vê a si próprio como civilizado, obrigando-se a levar as "grandes vantagens" 
de ser igual e livre aos que eles consideravam primitivos, logo não humanos, o que permitiu a exploração e a dominação desse outro que era visto como atrasado. Para isso, causou silenciamentos, esquecimentos e dissimulações de formas de conhecimento (ALMEIDA, 2018); (BERNARDINO-COSTA; GROSFOGUEL, 2016).

Já no período iluminista, que teve início do século XVIII, inaugurou o estudo voltado aos homens, o que possibilitou a comparação entre os diferentes grupos de pessoas, com a sua posterior classificação com base em características físicas. Claro que as revoluções liberalistas características do período iluminista foram importantes para acabar com o poder absoluto da nobreza. Porém, é importante perceber que enquanto os franceses lutavam ferozmente contra o poder absoluto da nobreza, temiam a libertação haitiana, com amarras que se mantêm até hoje, para o país ser independente (ALMEIDA, 2018).

Por isso, importante ressaltar que criaram uma universalidade de direitos que se voltava, novamente, a um único tipo de pessoa, especificamente, o homem branco, europeu, proprietário e cidadão. Assim, conforme leciona Achille Mbembe (2018), dentro da universalidade, o colonialismo explorou os corpos negros por meio da escravização, negandolhes a liberdade e a igualdade.

Nesse sentido, o sistema-mundo capitalista produziu e organizou, a partir de suas lógicas civilizatórias, um sistema econômico que coisifica e inferioriza algumas pessoas. Assim, o processo civilizatório retrata as relações de dominação de raça, gênero, sexo, epistêmico-pedagógica, de subjetividade/identidade, dentre outras, com padrões determinados por ele mesmo. Portanto, este projeto de morte genocida da vida e a destruiu epistemicamente outras civilizações, destruindo formas "outras" de conhecer, ser e estar no mundo (GROSFOGUEL, 2019).

Pelo exposto, vê-se que a América Latina foi a primeira periferia do sistema-mundo europeu (euro norte-americano), moderno, capitalista colonial e patriarcal, com oportunidade de acumulação primitiva do capital. A narrativa original que resgata e insere a América Latina como o continente fundacional do colonialismo e da modernidade, torna-o o primeiro laboratório de testes do racismo, por meio do colonialismo.

E sobre as relações raciais brasileiras especificamente, ressaltamos que a instituição escravocrata aconteceu por quase quatro séculos, enquanto um modelo econômico, político e social. A escravização indígena, quando inexitosa, trouxe a necessidade de escravização da civilização africana. Porém, ao atravessarem o Atlântico, foram reconhecidos e legitimados 
pela colonização aqui já imposta e atuante, mediante os paramentos de civilizados e primitivos, que se estendeu em uma relação entre brancos e negros. Momento em que se negou uma condição de humanidade às pessoas negras e se desvalorizou a cultura africana (LIMA, 2010).

Assim, é interessante perceber que, em 1850, aprovou-se a Lei Euzébio de Queiroz que repreendia intensamente o tráfico de novos escravizados africanos para o país. Esse fato trouxe como resultado o incentivo dos senhores à reprodução de novos escravos pelas mulheres negras escravizadas (LIMA, 2010).

Por isso, é indispensável perceber que os corpos femininos e masculinos escravizados eram vistos diferentemente. Enquanto os corpos masculinos eram possíveis guerreiros, ameaçadores e fortes, as mulheres carregavam o sinônimo de reprodução, causando seu estupro pelos colonizadores (MALDONADO-TORRES, 2020).

Diante da relação colonizado e colonizador na empresa colonial europeia, em que o colonizador impõe sua universalidade ao colonizado, permanecem as relações de poder e dominação baseadas no colonialismo, mesmo sem a existência formal de colônias, característica da colonialidade (LIMA; BORGES, 2019).

Por isso que apesar de hoje estarmos inseridos em período de pós-colonialismo, isso não significa que os efeitos da dominação colonial estão extintos, pois permanecem os conflitos estabelecidos em decorrência das relações de poder, mesmo com a suspensão das colônias (BERNARDINO-COSTA; GROSFOGUEL, 2016).

O pensamento decolonial, neste sentido, busca descolonizar o saber, em que se impôs o pensamento hegemônico, da forma mais violenta possível, subalternizando outras categorias e formas de estar no mundo, consequentemente, criando hierarquias sociais. Portanto, praticamente se extinguiram cosmovisões originais, impondo ao inferiorizado reaprender tudo com base no que o colonizador entende por correto (BERNARDES, 2018).

Assim, podemos perceber, com todo o destaque feito até este momento, que o racismo marca a realidade de pessoas negras desde o período de expansão que se iniciou no século XIV, mantendo-se mesmo com as revoluções iluministas, que se diziam muito libertadoras, consagrando o racismo. Especialmente quando pontuamos a realidade de mulheres negras, atravessadas pelo racismo e pelo sexismo

Destacamos, nesse sentido, que a interseccionalidade se dá sobre as interações das várias estruturas de poder nas vidas das minorias, bem como as consequentes formas de 
dominação ou de discriminação. A autora da teoria, defensora dos direitos civis, americana e feminista negra, Kimberlé Crenshaw (2002b), trata a interseccionalidade como forma de mostrar as consequências das formas de subordinação: sexismo, racismo, patriarcado. Não estudando apenas a figura da mulher, mas também todas as marcas da opressão que estão naquele corpo.

Diante do exposto, em busca do reconhecimento da pluralidade de mulheres, a Lei Maria da Penha inclui categorias de raça, orientação sexual e etnia. Contudo, a violência doméstica e familiar contra a mulher tem por base o gênero e, em especial, nas relações da vida conjugal (SANTOS, 2008) e nessa categoria especialmente, a violência é unificada com base no gênero.

Por este motivo, a Lei Maria da Penha precisa afirmar uma perspectiva interseccional para incluir mulheres lésbicas, trans, deficientes ou qualquer outra complexidade que marca cada mulher (CAMPOS, 2017) e, essencialmente, mulheres negras. Mas a questão também deve ser enfrentada internamente, entre as mulheres: que mulheres a lei exclui ou prejudica? O prejuízo legal é o mesmo para as mulheres em desvantagem econômica? Dessa forma, evita-se o essencialismo e se reconhece que o gênero é um dos marcadores que, associado a outros, confere diferentes opressões ou subordinações às mulheres (CAMPOS, 2011).

Nessa perspectiva precisamos ressaltar o feminismo negro brasileiro que é resultado das lutas sociais do final de 1970, fortificando-se em 1980, no Rio de Janeiro, com o grupo Nizinga, buscando a inclusão das mulheres negras na construção de um novo feminismo. Para isso, revelou que o feminismo branco e hegemônico não nomeia os problemas de mulheres negras e acaba por inviabilizá-las. Não só no movimento feminista hegemônico, mas também dentro dos movimentos negros, elas questionam seu papel secundário, diante da importância do papel das mulheres negras e suas condições específicas (MOREIRA, 2017); (RIBEIRO, 2016).

Especificidade essa que é bem descrita por Lelia Gonzalez (1984) na oportunidade em que descreve o carnaval e traz a clarividência que o mito da democracia racial ganha neste momento, tornando a mulher negra em rainha que é desejada pelos príncipes loiros que vieram de longe para vê-la. Do outro lado deste endeusamento está o dia a dia de mulheres domésticas, que são também a mulata desejada no carnaval, a depender da situação em que ela se encontra em cada momento. 
Uma outra figura importante destacada pela autora é a mãe bá, que criou os filhos das mulheres brancas (GONZALES, 1984), o que demonstra que o Brasil é um país amefricano, demarcado por um racismo por denegação, que inferioriza pessoas negras, mas diz que não o faz, diante da ideia de democracia racial. Mas, o pretoguês, falado no Brasil, muito diferente daquele falado em Portugal (GONZALES, 1988), demonstra que a criação dos brasileiros pela mãe bá, nos coloca em uma condição específica.

Assim destacamos a necessidade de estudos e políticas públicas sobre a violência doméstica, trabalharem com a interseccionalidade.

\section{A LEI MARIA DA PENHA EM UM OLHAR PARA AS MULHERES NEGRAS: BARREIRAS JURÍDICAS E LEGAIS, BEM COMO OS LIMITES DO CAMPO DE ATUAÇÃO}

Por todo o exposto até este momento analisamos que a universalidade dos direitos humanos não consegue abarcar todas as pessoas de forma efetiva, o que acontece com a universalidade de violência doméstica, trabalhada pela Lei Maria da Penha, sem prever a diversidade de intersecções presentes nas realidades de cada mulher, em especial de mulheres negras. Assim, buscamos agora demonstrar as barreiras que a legislação representa para algumas mulheres.

A lei em questão propôs um tratamento interdisciplinar, intersetorial e integral. Porém, isso resultou no mal-estar das instituições jurídicas, que estavam ligadas a ela pela característica de delito de menor potencial ofensivo que anteriormente caracterizava a violência doméstica, em um âmbito quase que privado. Motivo pelo qual profissionais relutam em cumpri-la de forma efetiva, por vezes tentam adequar essas perspectivas novas aos paradigmas tradicionais. Isso comprova a não absorção total dessa nova abordagem (CAMPOS, 2017a).

O que acontece porque o texto legal passa a ter diferentes interpretações na comunidade jurídica, muitas vezes distantes da interpretação feminista sobre o tema. Assim, silencia-se a produção interdisciplinar e política sobre causas e contornos para o problema (BERNARDES, 2019).

Apesar da grande repercussão da lei, ainda existem desafios para a implementação dela de forma efetiva diante dessa resistência dos operadores do direito, por isso que uma das 
grandes reivindicações dos movimentos de mulheres é a implementação de juizados especializados (SANTOS, 2008).

Essa resistência por parte dos profissionais demonstra a necessidade de focos na assistência e na prevenção, por meio do empoderamento das mulheres. Para isso, deve-se ter como prioridade mulheres negras, rurais, da mata, dos quilombos, indígenas, lésbicas, deficientes, aquelas que mais sofrem com a discriminação e a falta de acesso igualitário ao sistema judiciário. Assim, as políticas públicas devem priorizar a diversidade de mulheres. $\mathrm{O}$ que depende de mais recursos e de mais esforços dos agentes estatais em políticas públicas específicas (CAMPOS, 2017a, p. 9); (CAMPOS, 2015, p. 402).

Essa ideia também tem seus problemas, analisando-se que o Brasil é um país muito vasto e marcado por uma grande diversidade geográfica. Mas, principalmente porque as verbas para execução de políticas públicas se concentram nas capitais e regiões metropolitanas, deixando municípios menores de mãos atadas. Muitos deles sem nem ao menos compreender a importância do tema e a sua relação com problemas estruturais da sociedade. Além disso, a inexistência de políticas públicas específicas que salvaguardam as especificidades de mulheres, acabando por inviabilizá-las (CAMPOS, 2015).

Por isso, apesar da importância de dar visibilidade à diversidade de mulheres, esse é um desafio, que é aumentado pela amplitude e diversidade brasileira, resultando na revitimização de algumas mulheres e na exclusão de outras (CAMPOS, 2015, p. 401). Principalmente com as práticas de racismo, sexismo e homofobia que demarcam a realidade brasileira, por isso que mulheres negras, em suas mais diversas intersecções, são as maiores vítimas da violência doméstica (CAMPOS, 2017b).

É possível observar que os próprios movimentos de mulheres silenciam e selecionam demandas que lhes interessam, dando mais visibilidade a determinadas questões. Assim, pode-se visibilizar uma luta enquanto silencia outra, ou até mesmo conseguir uma conquista em detrimento de outra (SANTOS, 2008).

Por isso que as interseccionalidades de raça, de classe, de idade, geográfica, etc, vitimizam as mulheres de forma diferenciada e agravada (CAMPOS, 2017b). O racismo, a homofobia, a xenofobia, a discriminação com base na deficiência ou na idade, dentre inúmeras outras, intersectam com o sexismo e reproduzem a violência doméstica de forma diferenciada para cada mulher (SANTOS, 2017). 
Em análise aos dados do Atlas da Violência de 2020, nos marcadores de gênero e raça, constam que em 2018, a cada duas horas, uma mulher foi assassinada no Brasil, totalizando 4.519 mulheres ao todo. Isso representa 4,3\% dos homicídios em cada 100 mil habitantes do sexo feminino, método que exclui as mulheres transsexuais (IPEA, 2020).

O parecer também afirma que 19 das 27 Unidades Federativas (UF) brasileiras tiveram redução nas taxas de homicídios de mulheres nos anos de 2017-2018, porém, não anuncia a raça dessas mulheres. Os estados que apresentam os maiores índices para homicídios de mulheres, são também os Estados que apresentam os maiores índices para homicídios no geral, sendo esses: Roraima, Ceará e Acre. Em 2018 houve uma redução da violência letal contra as mulheres comparado aos anos mais recentes, ao observar um período mais longo, é possível verificar um incremento nas taxas de homicídios de mulheres no Brasil e em diversas UFs. Entre 2008 e 2018, o Brasil teve um aumento de 4,2\% nos assassinatos de mulheres (IPEA, 2020).

Apesar da redução de 8,4\% entre 2017-2018 dos homicídios femininos na última década, esse número melhorou apenas para mulheres não-negras, o que continua firmando o cenário de desigualdade social presente no Brasil. Entre os anos de 2017-2018, a queda de homicídios de mulheres não negras foi de $12,3 \%$, enquanto a redução de homicídio das mulheres negras foi de 7,2\%. Porém, analisando-se entre 2008-2018, enquanto a incidência de homicídios de mulheres não negras caiu $11,7 \%$, a taxa de homicídios de mulheres negras aumentou 12,4\%. Além disso, em 2018, 68\% das mulheres assassinadas no Brasil eram negras (IPEA, 2020).

O feminicídio, tipificado pela Lei $\mathrm{n}^{\mathrm{o}}$ 13.014/15 define como crime o homicídio de mulheres no contexto de violência doméstica e familiar, ou em decorrência de discriminação à condição da mulher, essas informações não são contabilizadas no Atlas da Violência de 2020. Todavia, ao analisar os homicídios das mulheres pelo local de ocorrência, percebe-se que entre 2013-2018 as taxas de homicídios de mulheres fora da residência foram de 11,5\%, enquanto a de mortes dentro de casa, aumentou para 8,3\% (IPEA, 2020), um indicativo do aumento significativo do feminicídio, reflexo do crescimento da difusão de armas de fogo, que aumentou de forma considerável nos últimos anos, principalmente com incentivo do atual governo.

O problema da violência masculina para com as mulheres continua crescendo sem projeções de diminuir, essa violência se difere das demais, pois está diretamente ligada às 
políticas do sexismo e da supremacia masculina: o direito dos homens de dominarem as mulheres (hooks, 2019). Fato que está intrinsecamente ligado a todos os atos impostos na sociedade, reforçando a ideia de que os poderosos dominam impotentes, voltando para aquela dualidade de dominador $\mathrm{x}$ dominado, homem x mulher, branco x negro.

Confirmando a relevância que a lei deveria ter no combate à violência doméstica contra mulheres negras. Observando os dados de violência, enquanto diminui o índice de mulheres brancas, o percentual para violências contra mulheres negras só aumenta. Por isso é indispensável pensar como as políticas públicas de enfrentamento a este problema reproduzem os privilégios da branquitude (BERNARDES, 2018).

Vivendo nessa sociedade racista e sexista que é o Brasil, não se pode silenciar o racismo como categoria de opressão e privilégio, mesmo nos casos de violência doméstica. Por isso é preciso reformas que valorizem as vítimas de violência, colocando-as como protagonistas no seu processo de superação contra a violência doméstica (BERNARDES, 2018).

Nesse sentido, destacamos o pensamento feminista negro em busca de resistir às opressões interseccionais, visando empoderar as mulheres negras no contexto de injustiça social sustentado pelas opressões interseccionais. Na ideia de que não podem ser plenamente empoderadas, o pensamento feminista negro apoia princípios de justiça social que transcendem as necessidades específicas das mulheres (COLLINS, 2019).

Os saberes coletivos de mulheres negras sedimentam interpretações predominantes a respeito da consciência dos grupos oprimidos. Inicialmente, perante a identificação dos grupos subordinados e a não interpretação da sua própria opressão validada e a posterior presunção de que os oprimidos não são tão humanos quanto aqueles que os dominam, assim menos capazes de interpretar suas próprias experiências. No período escravocrata, uma pauta emergente do pensamento feminista negro, era estupro institucionalizado das mulheres negras escravizadas que atuava como mecanismo de controle social, principalmente para com aquelas que trabalhavam na agricultura e no serviço doméstico (COLLINS, 2019).

As intersecções entre raça e gênero, gênero e classe, ou raça e classe, ou então gênero, raça e classe, são paradigmas que demonstram como que a opressão é transversal. Essa noção de dominação se refere à maneira que as opressões interseccionadas estão ordenadas nos poderes (COLLINS, 2019). 
Essa necessidade de dominação, são firmadas na necessidade de objetificar o grupo subordinado, tirar desse sujeito a ideia de que a pessoa tem o direito de definição da sua identidade, vontade e realidade, lhe é tirada a oportunidade de escrever e nomear sua própria história. Dessa forma: brancos governam os negros, os homens dominam as mulheres, esses espaços ocupam a opinião na avaliação do conhecimento, fazendo com que sujeitos governem os objetos. Os alicerces das opressões interseccionais se apoiam em conceitos interdependentes do pensamento binário, implicando em superioridade e inferioridade, formando vínculos hierárquicos que integram políticas de opressão de raça, gênero e classe (COLLINS, 2019).

As deficiências da lei acontecem pelos operadores do direito, quando não a aplicam de forma integral e protetiva. Por isso a necessidade de políticas públicas que abarquem as especificidades, mas principalmente as interseccionalidades que marcam a realidade de cada mulher, em especial para este artigo, de mulheres negras. Porém, isso é um problema, tendo em vista o baixo investimento em políticas públicas específicas para mulheres em situação de violência, e também porque essas verbas geralmente estão nos grandes centros e nas capitais, sem se preocupar com mulheres pobres e periféricas, presentes nos pequenos municípios.

O que se reflete na ideia trabalhada até o momento, de que a universalidade de direitos humanos, ou de formas de opressão, não consegue ser efetiva a toda e qualquer pessoa, marginalizando umas em detrimento de outras. Falta que se torna visível quando analisamos os índices de violência de mulheres, demonstrando o aumento para casos que envolvem mulheres negras e diminuição do caso de mulheres brancas. Por isso, a importância do pensamento feminista negro, no sentido de empoderar mulheres negras diante das injustiças sociais, por meio da resistência às opressões interseccionais.

\section{CONSIDERAÇÕES FINAIS}

Por todo o exposto, observamos que a Lei Maria da Penha é sim um grande marco do direito brasileiro, é conquista para as mulheres brasileiras e teve grande relevância de movimentos de mulheres em sua criação, colocando formas de opressão múltipla como diferenciadora de alguns casos.

Porém, por ser talhada nos moldes universais, acaba delimitando-se também, aos moldes universais. O que acontece porque ela unifica o que é violência com base única no 
gênero. Portanto, através deste artigo buscamos verificar de que forma a proteção das mulheres acontece, direcionando-se de forma muito especial às mulheres negras em situação de violência doméstica, pela perspectiva interseccional e decolonial.

Esse triunfo jurídico, notoriamente importante, infelizmente não abrange a todas as mulheres, o que não é um desmerecimento para a legislação, mas sim, uma indicação para a necessidade de uma ampliação e abrangência desta, como por exemplo, uma maior atenção às mulheres negras, mulheres trans e mulheres de baixa renda.

Nesse sentido, o pensamento feminista negro, compreende a perspectiva parcial de dominação da vida cotidiana das mulheres negras, principalmente quando gênero e raça operam juntos. A relevância da epistemologia feminista negra detém a capacidade compreensiva sobre o modo em que os grupos subordinados criam conhecimentos capazes de fomentar tanto seu empoderamento quanto a justiça social (COLLINS, 2019).

Quando cada grupo fala exclusivamente a partir de seu próprio ponto de vista, passa a compartilhar conhecimentos apenas parciais ou localizados. Essa parcialidade, não a universalidade, é uma condição necessária para se fazer ouvir seja no formato dos indivíduos e/ou dos grupos que fazem reivindicações de conhecimento sem reconhecer sua posição, são considerados menos confiáveis (COLLINS, 2019).

No caso das mulheres trans, elas têm muita dificuldade de acessar a Lei Maria da Penha, diante da resistência do Poder Judiciário, pelo argumento de não inclusão, por exemplo, da homofobia como uma violação. O que nos demonstra a importância que a interseccionalidade tem, pois apesar de não haver dúvidas sobre a proteção dessas mulheres, com a violência baseada no gênero, há o tradicionalismo que busca distorcer a lei (CAMPOS, 2017b), conforme pontuamos ao final do artigo. O que demonstra que, de fato, o universalismo não abrange todas as mulheres, limitando-se, muitas vezes, às mulheres, brancas, cisgêneros, heteronormativas e de condição social favorável.

Por esse motivo, políticas públicas devem ser focadas na diversidade de mulheres em sua vida concreta, analisando marcadores de vulnerabilidades específicas (CAMPOS, 2017b). Por isso, as formas de opressão e privilégio que acontecem múltipla e interseccionalmente precisam estar mais presentes em estudos sobre a violência doméstica, mas principalmente em políticas públicas (SANTOS, 2017).

Porém, partimos da ideia de que intelectuais não podem falar pelos oprimidos/as, pois corremos o risco de cair naquela ideia hegemônica de objetificação das mais oprimidas 
pela violência doméstica, reproduzindo as estruturas hierarquizadas de poder que tanto criticamos. Por isso é vital a escuta dessas mulheres mais vitimizadas, lutando em conjunto contra as estruturas produtoras da subalternidade (BERNARDES, 2018).

Finalizamos, diante de todo o exposto, afirmando a importância de uma luta antissexista, mas que esteja em união com o antirracismo, para que possamos findar com as bases hegemônicas de poder de forma realmente verdadeira, pois, conforme destacamos ao longo do artigo, apesar de importâncias legais e jurídicas conquistadas pelos movimentos de mulheres em relação à violência doméstica, não consegue ser efetiva de forma geral. Isso acontece porque silencia, ou simplesmente não escuta, outras mulheres também vitimizadas por ela.

\section{REFERÊNCIAS}

ALMEIDA, Silvio Luiz de. O que é racismo estrutural? Belo Horizonte: Letramento, 2018.

BENTO, Maria Aparecida da Silva. Branqueamento e Branquitude no Brasil. In: CARONE, I; BENTO, M. A. S. (Org.). Psicologia social do racismo: estudos sobre branquitude e branqueamento no Brasil. Petrópolis: Vozes, 2002, p. 25-58.

BERNARDES, Márcia Nina. Aspectos transacionais da luta contra a violência doméstica e familiar no Brasil. Direito, Sociedade e Estado, n. 45, jul./dez. 2014, p. 119-144.

. Problemas de gênero na jurisprudência brasileira: (Des)fazendo a Lei Maria da Penha. Direito, Estado e Sociedade, n. 55, jul./dez. 2019, p. 231-256.

Racializando o feminicídio e a violência de gênero: reflexões sobre a experiência brasileira. In: Gênero e direito: desafios para a despatriarcalização do sistema de justiça na América Latina, Rio de Janeiro, 2018.

BERNARDINO-COSTA, Joaze; MALDONADO-TORRES, Nelson; GROSFOGUEL, Ramón. Decolonialidade e pensamento afrodiaspórico. Belo Horizonte: Autêntica, 2019. p. 55-77.

CAMPOS, Carmen Hein de. Desafios na implementação da Lei Maria da Penha. Revista Direito GV, São Paulo, v. 11, n.2, jul./dez. 2015, p. 391-406.

(Org.). Lei Maria da Penha: comentada em uma perspectiva jurídico-feminista. Rio de Janeiro: Lumen Juris, 2011.

. Lei Maria da Penha: uma segunda virada paradigmática. In: Seminário Internacional

Fazendo Gênero 11 e 13 $^{\circ}$ Mundos de Mulheres; Florianópolis, 2017. Disponível em: 
<https://www.en.wwc2017.eventos.dype.com.br/resources/anais/1497988820_ARQUIVO_L MPumasegundaviradaFG2017.pdf> . Acesso em: 25 set. 2020.

CÉSAIRE, Aimé. Discurso sobre o colonialismo. Lisboa: Livraria Sá da Costa Editora, 1978.

COLLINS, Patrícia Hill. Pensamento Feminista Negro: conhecimento, consistência e a política de empoderamento. São Paulo: Boitempo, 2019. 493 p. Tradução: Jamille Pinheiro

CRENSHAW, Kimberlè. A interseccionalidade na discriminação de raça e gênero. Painel 1 Cruzamento: raça e gênero, [S. I.], 2002a, p. 7-16.

. Documento para o encontro de especialistas em aspectos da discriminação racial relativos ao gênero. Estudos Feministas, Florianópolis, Santa Catarina, v.7, n. 12, jan. 2002b, p. 171-188.

FANON, Frantz. Os condenados da Terra. Rio de Janeiro: Civilização Brasileira, 1997. Tradução: José Laurêncio de Melo.

FLORES, Joaquín Herrera. A reinvenção dos direitos humanos; tradução de Carlos Roberto Garcia; Antônio Henrique Graciano Suxberger; Jefferson Aparecido Dias. Florianópolis: Fundação Boiteux, 2009.

GONZALES, Lélia. A categoria político-cultural de amefricanidade. Rev. Tempo Brasileiro, Rio de Janeiro, n. 92-93, jan./jun. 1988, p. 69-82.

. Racismo e sexismo na cultura brasileira. In: IV Encontro Anual da Associação

Brasileira de Pós-graduação e Pesquisa nas Ciências Sociais. Rio de Janeiro, out. 1984.

hooks, bell. Teoria feminista: da margem ao centro; tradução de Rainer Patriota. São Paulo: Perspectiva, 2019.

Mulheres negras: moldando a teoria feminista. Revista Brasileira de Ciência Política, [S.I.], n. 16, abr. 2015, p. 193-210.

IPEA, Instituto de Pesquisa Econômica Aplicada. Atlas da Violência. Brasília: IPEA, 2020.

KILOMBA, Grada. Memórias da plantação: episódios de racismo cotidiano; tradução de Jess Oliveira. Rio de Janeiro: Cobogó, 2019.

LIMA, Fernanda da Silva. A proteção integral de crianças e adolescentes negros: um estudo do sistema de garantia de direitos para a promoção de igualdade racial no Brasil. 2010. 320p. Dissertação (Mestrado) - Curso de Mestrado em Direito - Universidade Federal de Santa Catarina, Florianópolis, 2010.

LIMA, Fernanda da Silva; BORGES, Gustavo. Publicidade e racismo reverso: o que uma campanha publicitária tem a revelar sobre o racismo no Brasil. Revista de Direito do Consumidor, São Paulo, v. 123, ano 28, maio/jun. 2019, p. 37-76. 
MACHADO, Isadora Vier (Org.). Uma década de Lei Maria da Penha: percursos, práticas e desafios. Curitiba: CRV, 2017.

MIÑOSO, Yuderkys Espinosa. Sobre por que é necessário um feminismo decolonial: diferenciação, dominação constitutiva da modernidade ocidental. In: Terceiro seminário sobre Arte e Descolonização; 2020, São Paulo. Disponível em: <https://masp.org.br/arte-edescolonizacao>. Acesso em: 25 set. 2020.

MOREIRA, Núbia Regina. Feminismo negro brasileiro: igualdade, diferença e representação. In: $31^{\circ}$ Encontro da ANPOCS, Caxambu, 22-26 out. 2007.

OLIVEIRA FILHO, Pedro de. A mobilização do discurso da democracia racial no combate às cotas para afrodescendentes. Estudos de Psicologia, Campinas, v. 26, n. 4, out./dez. 2009, p. 429-436.

RIBEIRO, Djamila Feminismo negro para um novo marco civilizatório. SUR: ensaios, v. 13, n. 24, 2016, p. 99-104.

O que é: lugar de fala? Belo Horizonte: Letramento: Justificando, 2017.

SANTANA, Andreia. bell hooks: uma grande mulher em letras minúsculas. Mar de histórias, mar. 2009. Disponível em: <https://mardehistorias.wordpress.com/2009/03/07/bellhooks-uma-grande-mulher-em-letras-minusculas/>. Acesso em: 25 set. 2020.

SANTOS, Cecília MacDowell. Da delegacia da mulher à Lei Maria da Penha: lutas feministas e políticas públicas sobre violência contra mulheres no Brasil. Centro de Estudos Sociais, Coimbra, Oficina n. 301, mar. 2008. 